\title{
CONSIDERAÇŌES SOBRE A OCORRÊNCIA DE CACTACEAE NA APA DE MARICÁ, RIO DE JANEIRO, BRASIL
}

\author{
Cecília Maria Rizzini ${ }^{1}$ \\ Cézio Pereira' \\ Elena Maria de Lamare Occhioni' \\ Fernando Vieira Agarez'
}

\begin{abstract}
RESUMO - São estudadas as espécies da família Cactaceae que ocorrem na Restinga de Maricá, cuja flora se encontra ameaçada devido a diversas interferências que vêm alterando sua composição florística e vegetacional. São citadas 4 novas ocorrências para o local e observações de campo.
\end{abstract}

Palavras-chave: Cactaceae, Restinga de Maricá, Taxonomia

ABSTRACT - The species of Cactaceae which occur at "Restinga de Maricá" were studied. These taxa are threatened by extinction, due two diverse interferences that are changing the floristic and vegetational composition of the area. Four new occurrences for the location are mentioned and field observations are given.

Key-words: Cactaceae, Restinga de Maricá, Taxonomy.

\section{Introdução}

A Restinga de Maricá integra uma área de proteção ambiental ameaçada de extinção pela ocupação humana com o avanço da construção civil, além de diversas outras interferências que vem alterando significativamente sua composição florística e vegetacional, como retirada de areia das dunas, coleta de mudas para comercialização, queimadas, cortes sistemáticos de espécimes para obtenção de lenha, etc.

Assim, torna-se imperativo que se tenha um conhecimento pleno de sua flora através de estudos taxonômicos e ecológicos, assim como se intensifique as coletas científicas para inclusão em herbários reconhecidos.

A família Cactaceae, embora com somente 11 espécies detectadas até o momento, está amplamente difundida nesta região. Já citadas na literatura e/ou registradas em herbários encontramos Cereus obtusus Haw., Pilosococereus arrabidae (Lem.) Byles \& Rowl., Lepismium cruciforme (Vell.) Miquel, Rhipsalis prismatica (Lem.) Forst \& Rumpl., Selenicereus rizzinii Scheinvar,

1 - Professores do Departamento de Botânica, Instituto de Biologia UFRJ. Ilha do Fundão, ZC-32. Auxílio CEPEG. 
Rhipsalis pachyptera Pfeiff. e Pereskia aculeata Mill., todas com exceção da última, com ampla distribuição na área.

Este estudo permitiu ampliar as listagens existentes sobre a flora de Maricá, com o registro de 4 ocorrências novas para a região: Melocactus melocactoides' (Hoffm.) DC., encontrada somente numa pequena comunidade com 5 exemplares; Opuntia vulgaris Mill. e Brasiliopuntia brasiliensis (Willd.) Berg., com poucos exemplares restritos a determinadas áreas e Rhipsalis baccifera (Mill.) Stearn., com 2 exemplares epífitos encontrados perto de habitações.

\section{Material e Métodos}

A área estudada engloba a área de proteção ambiental do município de Maricá, Estado do Rio de Janeiro, distante 130 km do município do Rio de Janeiro.

Foram realizadas excursões periódicas (geralmente quinzenais) para coleta de espécimes, documentário e observações in loco do comportamento dos mesmos dentro das comunidades em que ocorriam. As coletas foram feitas por varredura e praticamente todas as espécies possuem amostras com flor e fruto. O material foi depositado no Herbário do Departamento de Botânica do Instituto de Biologia (sigla RFA). Foram consultados, além do Herbário acima referido, os Herbários do Museu Nacional da UFRJ (sigla R) e do Jardim Botânico do Rio de Janeiro (sigla RB).

O estudo taxonômico das espécies incluiu chave para gêneros e espécies, quando necessário; pequenas descrições das plantas; atualização da nomenclatura, sendo que só foram citados os sinônimos que ainda são utilizados incorretamente pelos botânicos; nomes vulgares bem conhecidos; citando-se somente material coletado dentro da área preestabelecida para o estudo; observações sobre ocorrência, etc.

Todas as espécies foram fotografadas em flor e ou fruto em seu habitat, bem como detalhes de sua morfologia.

O levantamento bibliográfico referiu-se à literatura do grupo taxonômico em pauta, como monografias, revisões, etc.

\section{Resultados e conclusões}

Os estudos de campo realizados permitiram dividir a área em 7 gradientes com aspectos florísticos e vegetacionais distintos, a saber: (Figura 1) 

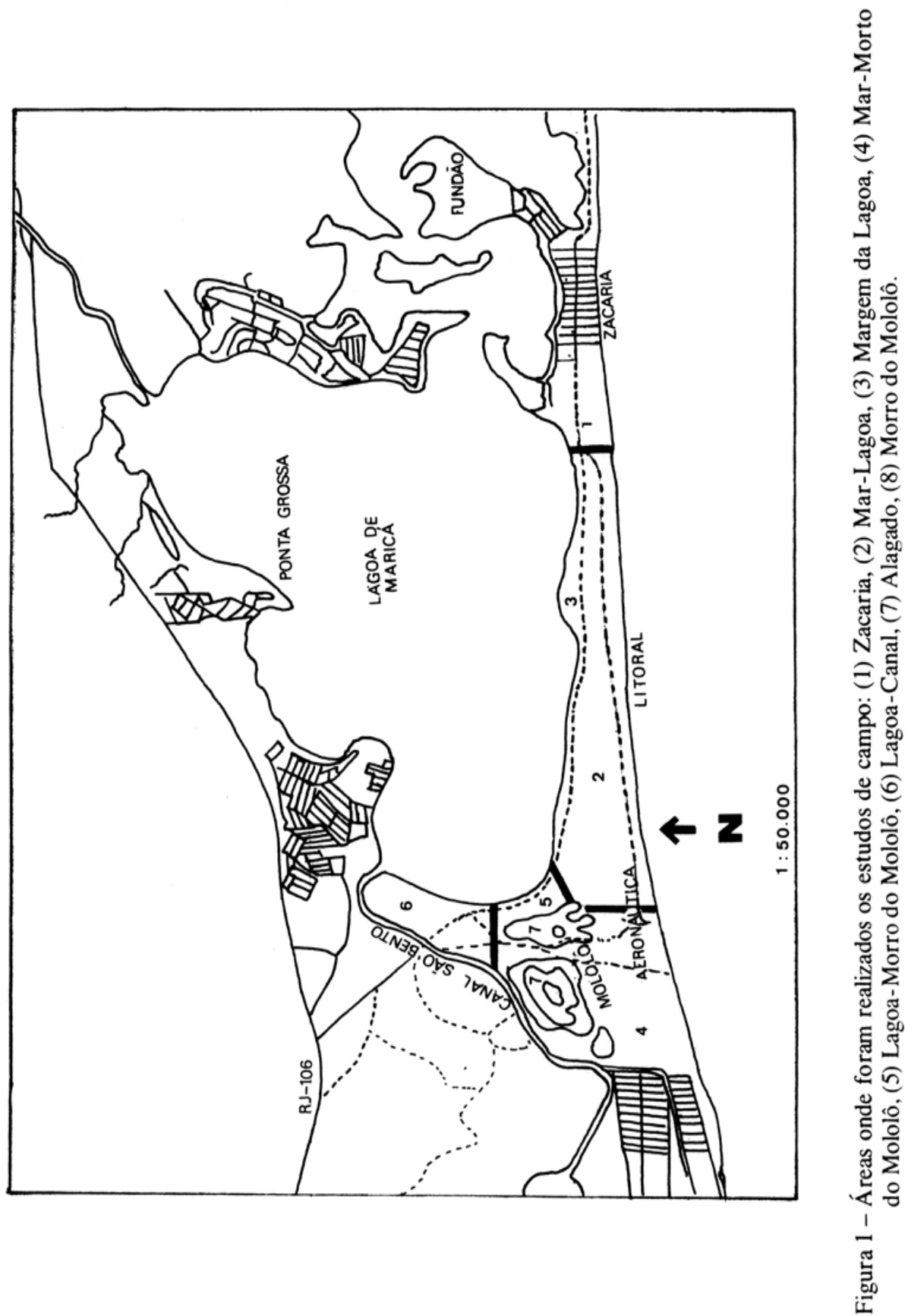
1. Área junto à comunidade pesqueira de Zacaria: corresponde a uma grande área completamente desmatada, onde o solo é recoberto basicamente por gramíneas e algumas moitas baixas de cactáceas, bromeliáceas e mirtáceas. São comuns brotações novas de sapotáceas, lauráceas, apocináceas e também algumas plantas, introduzidas.

2. Mar-Lagoa: com dois cordões arenosos, sendo o próximo ao mar equivalente à duna secundária e o próximo à lagoa, a duna primária. No primeiro, predomina uma vegetação herbácea subarbustiva cortada por uma estrada litorânea. No segundo, as plantas são em geral arbustivas e se agrupam em moitas esparsas, de tamanho variável, permitindo a circulação entre elas.

3. Margem da Lagoa: vegetação rasteira com predomínio de gramíneas, ciperáceas e tifáceas.

4. Mar-Morro do Mololô: inicialmente é representada por uma vegetação subarbustiva fechada, sem possibilidade de livre circulação. À medida que se afasta do mar, e se aproxima do Mololô, a vegetação torna-se gradativamente mais alta, até atingir o porte arbóreo, formando uma mata alta com dossel aproximado de $10 \mathrm{~m}$ de altura, onde a luz praticamente não penetra e a circulação é relativamente fácil. No subbosque são encontradas espécies de bromeliáceas, orquidáceas, piperáceas, cactáceas, gesneriáceas, comelináceas e iridáceas, entre outras.

5. Lagoa - Morro do Mololô: inicialmente a restinga apresenta-se com as plantas dispostas em muitas de diferentes tamanhos e formatos, que permitem a livre circulação entre elas; gradàtivamente, as moitas vão se agrupando e a vegetação passa a ser arbórea, permitindo razoável circulação. Esta fisionomia aproxima-se do pé no morro, onde inicia-se a transição entre a restinga (solo arenoso) e a vegetação secundária do morro (solo argiloso).

6. Lagoa - Canal de São Bento: faixa de restinga bastante alterada pela ação antrópica. Junto à lagoa pode-se observar restos de restinga arbórea, com árvores de $10-12 \mathrm{~m}$ de altura. No restante, a vegetação se dispõe em moitas. É comum o aparecimento de plantas exóticas e ou cultivadas.

7. Morro do Mololô: apresenta-se com algumas partes completamente desmatadas, recobertas por vegetação graminóide. No mais, a vegetação é de capoeira fechada com alguns exemplares arbóreos remanescentes (vegetação secundária).

\section{Chave para gêneros}

1. Plantas terrestres

2. Caule articulado

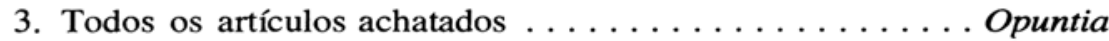

3' Sem esta característica ............... 4 
4. Artículos cilíndricos, deles partido os achatados $\ldots \ldots \ldots \ldots \ldots$

$\ldots \ldots \ldots \ldots \ldots \ldots \ldots$. . . . . . . . . . . . . . . . . . . . . . .

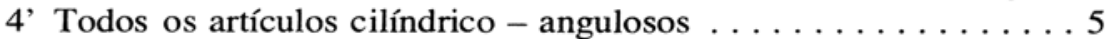

5. Raramente com mais de $1 \mathrm{~m}$ de altura; cladódios com 3-5 ângulos; bagas elipsóides, violáceas e com polpa branca ....... Cereus

5' Até 3m de altura; cladódios com 6-8 ângulos; bagas globosas, achatadas, verdes e com polpa sangüínea...... Pilosocereus

2' Caule não articulado

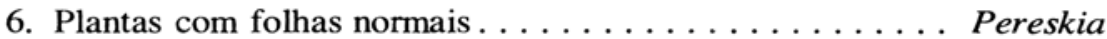

6' Plantas sem folhas................ Melocactus

1' Plantas epífitas ou escandentes

7. Artículos de seção subcircular ou trialada, flores de $15-35 \mathrm{~cm}$ de com-

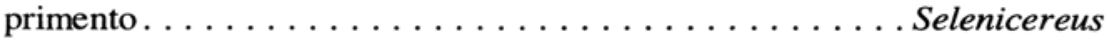

7' Artículos aplanados ou cilíndricos, flores com cerca de $1 \mathrm{~cm}$ de com-

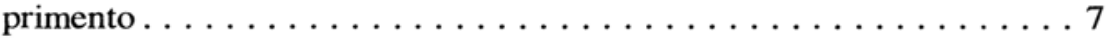

8. Frutos inclusos nas aréolas, estas com abundante lanosidade Lepismium

8' Sem estas características $\ldots \ldots \ldots \ldots \ldots \ldots$ Rhipsalis

\section{Descrição das espécies}

Opuntia (Tourn.) Mill.

Opuntia vulgaris Mill. Gard. Dict. ed. 8, 1:16. 1768.

Planta ramificada, 1-2m de altura, com artículos achatados e carnosos; aréolas marginais ou dispostas alternadamente, tomentosas, 1-2 espinhos agudos e de comprimento variado, resistentes. Botões florais vermelhos; flores solitárias, rotáceas, amarelas, segmentos externos do perianto com estrias avermelhadas, $5-6 \mathrm{~cm}$ de diâmetro na antese. Fruto baga, piriforme, $4-5 \mathrm{~cm}$ de comprimento, epicarpo espesso e aréolas esparsas.

Nome vulgar: Palmatória (Correa, 1984)

Material coletado: RFA no 22.093, C.M. Rizzini et al., 425, 16.V. 1988, fr.; RFA no 22.220, C. Pereira s.no, 10.X.1988, fl.; RFA no 22.638, C.M. Rizzini et al.,450, 28.XI.1988, fl. fr.

Observações: espécie pouco freqüente, mas de presença marcante, observada somente nos gradientes 5 e 6 , sendo os exemplares de pequeno tamanho. Não foi encontrada nos herbários examinados, nem citada na literatura pertinente para Maricá, embora seja uma espécie muito comum nas nossas restingas e de fácil identificação. 
Brasiliopuntia (K. Schum.) Berg.

Brasiliopuntia brasiliensis (Wild.) Berg., Entwiklungsl. Kakt. 94.126; Scheinvar, Cactáceas in Fl. Catar. 1:52. 1985.

Opuntia brasiliensis (Willd.) How., Suppl. Pl. Succ. 8:79. 1819.

Planta arbórea até $5 \mathrm{~m}$ de altura, tronco cilíndrico, acinzentado, espinhoso. Primeiros artículos cilíndricos, dos quais partem artículos aplainados e foliáceos; aréolas espiraladas, de diferentes dimensões e coloração nos dois tipos de artículos; normalmente espinho acicular disposto no bordo dos artículos. Flores amarelas, nos bordos dos artículos, mais ou menos $5 \mathrm{~cm}$ de diâmetro na antese. Fruto globoso, $3-4 \mathrm{~cm}$ de diâmetro, epicarpo com aréolas circulares com gloquídeos marrom-avermelhados.

Nome vulgar: Arumbeva-açu (Scheinvar, 1985), jumbeba e palmatória grande (Correa, 1984).

Material coletado: RFA no 22.092, C.M. Rizzini et al. 242, 16.V. 1988, Fr.; RFA no 22.534, C.M. Rizzini et al. 442, 25.X. 1988, fl.; RFA no 22.218, C. Pereira s.no., 3.X.1988, fl.

Observações: Esta espécie, ainda citada por alguns pesquisadores pelo sinônimo. $\boldsymbol{O}$. brasiliensis, está sendo aqui indicada pela primeira vez para Maricá. Ocorre bem pouco na região, com pés isolados encointrados nos gradientes $4 \mathrm{e}$ 5 , em geral do interior da restinga arbórea.

\section{Cereus Mill.}

Cereus obtusus Haw., Syn. Pl. Succul. 1821.

C. pernambucensis Lem., Nov. Cact. Gen. Sp.: 58.1839.

Planta raramente chegando a $1 \mathrm{~m}$ de altura, cladódios com 3-6 ângulos paralelos e 4-5 cm de diâmetro; aréolas com 1,5-2,0 cm de distância entre si, pardo-tomentosas ou lanosas; espinhos fasciculados de tamanhos desiguais, sendo o central maior e solitário. Flores infundibuliformes, solitárias, $20-23 \mathrm{~cm}$ de comprimento, brancas, noturnas, aculeadas na base. Bagas elipsóides, violáceo-claras e com polpa branca e acídula, comestível.

Nome vulgar: Cardo-da-praia (Correa, 1984).

Material coletado: RFA n- 22.196, C.M. Rizzini et al., 25.X.1988, fr; RFA no 22.536, C.M. Rizzini et al., 25.X.1988, fl.

Observações: Espécie extremamente freqüente em quase todos os gradientes, 
principalmente $1,2,4,5$ e 6 . Apesar de sua nomenclatura ter sido alterada por Ritter (1979), ainda é tratada pelo sinônimo $C$. pernambucensis pela maioria dos botânicos; é muito procurada, pelo sabor agradável de seus frutos.

Pilosocereus Byles et Rowl.

Pilosocereus arrabidae (Lem.) Byles et Rowl. in Cact. et Succ. Journ. Brit. 19:66.1957.

Planta com 2-4m de altura, cladódios com 6-8 ângulos paralelos e 5-8 cm de diâmetro, aréolas com cerca de $1 \mathrm{~cm}$ de distância entre si e bastante lanosas; 7-9 espinhos sendo, geralmente, 4 maiores centrais e os restantes menores e periféricos. Flores geralmente localizadas na região terminal do cladódio, brancas, 7-9 cm de comprimento, solitárias, branco-esverdeadas. Bagas globoso-achatadas, verdes, com polpa sangüínea viscosa e insípida.

Material coletado: RFA no 22.094, C.M. Rizzini et al., 426. 16.V. 1988, fl; RFA no 22.095, C.M. Rizzini et al. 427. 16.V.1988, fr.

Observações: Espécie bastante comum em toda a restinga, principalmente nos gradientes 1, 2, 4, 5 e 6. Quando jovem, assemelha-se à primeira vista com Cereus obtusus Haw., destacando-se, principalmente, pela abundante lanosidade na região apical do cladódio. Seus frutos são comestíveis, embora não possuam o sabor especial dos frutos de Cereus obtusus.

\section{Pereskia (Plum.) Mill}

Pereskia aculeata Mill., Gard. Dict. Abridg. ed. 8. 1968; K. Schum, Cactaceae in Mart. Fl. Bras. 4(2): 3-12-1890; Schveinvar, Cactáceas in Fl. Catar. 1:11.1985.

P. peireskia (L.) Karsten, Deutsche Fl.: 888.1892.

Planta escandente com 3-4m de altura, tronco lenhoso com aréolas providas de espinho solitário. Folhas laminares ovadas, curtamente pecioladas 2$5 \mathrm{~cm}$ de largura. Flores branco-cremosas, perfumadas, dispostas em panículas, períginas, 1-2-5 cm de compri,mento; estames desiguais, brancos ou vermelho-rosados, 10-15 mm de comprimento. Fruto carnoso, globoso, amarelado ou alaranjado, $0,51 \mathrm{c} \mathrm{cm}$ de diâmetro, com aréolas providas de espinhos e folhas verdes (caducas quando o fruto está maduro).

Nome vulgar: ora-pro-nobis (Correa, 1984 e Scheinvar, 1985).

Material coletado: RFA no 22.216, C. Pereira s.no., 30. V.1988, fl.; 
RFA no 22.096, C.M. Rizzini et al., 429. 16.V.1988, fr.

Observações: Espécie pouco freqüente, encontrada próximo ao Morro do Mololô (grad. 5-5). Ainda citada na literatura, pela maioria dos autores, como $P$. peireskia.

Selenicereus (Berger) Britt. et Rose

Selenicereus rizzinii Scheinv., Rev. Bras. Biol. 34(2): 249-252. 1974; Ibid., Cactáceas in Fl. Catar. 1:112. 1985.

Planta escandente, com inúmeras raízes adventíceas. Artículos geralmente triangulares, podendo chegar a ter 8 costelas; aréolas com lanosidade marrom, distantes até $5 \mathrm{~cm}$ entre si, com cerca de $5 \mathrm{~mm}$ de diâmetro; espinhos de número variado, radiais com 1 central, curtos e rígidos. Flores noturnas, infundibuliformes, brancas, $20-25 \mathrm{~cm}$ de comprimento, com aréolas dispostas em 5 séries espirais, androceu e gineceu inclusos. Fruto baga elipsóide, indeiscente, quando maduro rosa-escuro e com cerca de 9-10 $\mathrm{cm}$ de comprimento e 6-7 $\mathrm{cm}$ de largura, polpa branca e saborosa (ligeiramente doce).

Nome vulgar: Cardo-ananás (nome local), Rainha-da-noite (Correa, 1984), Dama-da-noite (Scheinvar, 1985).

Material coletado: RFA no 22.643, C.M. Rizzini et al., 6.XII:1988, fl.; RFA no 22.618, C.M. Rizzini et al., 448. 21.XI.1988, fl.; RFA no 26.215, C. Pereira s.no, 3.X.1988, fl.; RFA no 22.214, C. Pereira s.no, 22.IX.1988, fl.; RFA no 22.538, C.M. Rizzini et al., 446. 25.X.1988; fl.

Observações: Espécie bastante freqüente no gradiente 2, principalmente. Ornamental devido a suas belas e grandes flores. O fruto é comestível e bastante saboroso. Indicada erradamente para Maricá por. diversos autores como $S$. setaceus (S.-D.) Berg. e como Mediocactus coccineus Britton et Rose.

\section{Melocactus Link et Otto}

Melocactus melocactoides (Hoffm.) DC., Prodr. Syst. Regn. Veget. 3:461. 1828; C.T. Rizzini, Melocactus no Brasil, p. 79. 1982. M. violaceus Pfeiff. Allg. Gartenztg. 3:313. 1835.

Planta de corpo globoso-cônico, 8-9cm de comprimento, $9 \mathrm{~cm}$ de largura. Espinhos periféricos, 7-8, caracteristicamente de cor acinzentada, sendo 1 central e 6-7 radiais (2 de menor tamanho). Cefálio abaulado, esbranquiçado, com poucas cerdas rubras periféricas, cerca de $6 \mathrm{~cm}$ de diâmetro; flores baixas 
e aplicadas sobre o cefálio, violáceas. Frutos clavados, rosados, 1-1,5 cm de comprimento.

Nome vulgar: Cabeça-de-frade (Correa, 1984)

Material coletado: Foram encontrados apenas 5 exemplares reunidos em uma pequena população, em restinga baixa de moitas esparsas (grad. 5). A descrição limita-se ao exemplar mais desenvolvido e na época, em flor e fruto (em cultivo no laboratório).

Observações: Não existe indicação da ocorrência desta espécie para Maricá, tanto na literatura quanto nos herbários consultados. Seguramente trata-se da variedade melocactoides que, segundo Rizzini (1982), ocorre em Macaé, RJ. A variedade itapuassuensis Rizz., embora ocorrendo adjacente à Maricá, conforme o nome aponta, possui o corpo globoso ou globoso-deprimido, característica não encontrada nos exemplares observados.

\section{Lepismium Pfeiffer}

Lepismium cruciforme (Vell.) Miq., Bull., Sci Nat. Neerl.: 49. 1938; Scheinvar, Cactáceas in Fl. Ilustr. Catar. 1:162. 1985.

Planta epífita, escandente ou rasteira, até $1 \mathrm{~m}$ de comprimento, com raízes adventícias abundantes. Artículos com 3-4 ângulos crenados, verde-escuros ou acinzentados, às vezes com bordos avermelhados. Aréolas com bordos avermelhados e abundantes pêlos esbranquiçados. Flores geralmente solitárias, imersas na aréola e com cerca de $1 \mathrm{~cm}$ de diâmetro; coloração de branca a avermelhada quando novas, passando a alaranjadas na maturação. Fruto baga, vermelho, com 4-7 mm de diâmetro.

Nome vulgar: Cruzeta (Scheinvar, 1985).

Material examinado: RFA no 22.151, C.M. Rizzini 431 et al., 4.VII.1988, fl.; RFA no 22.489, C.M. Rizzini 441 et al., 3.X.1988, fl.; RFA no 22.619, C.M. Rizzini 449 et al., 21.XI.1988, fl.; RFA no 18.534, P. Occhioni 8.306 et al., 13.II.1978, fl.; RB no 172.097, D. Araújo 766 et al., 8.IX.1975, Fl. e Fl.; RB no 178.624, Col. D. Araújo 677 et al., 16.IV.1975, fl. e fr.

Observações: Espécie bastante freqüente e quando exposta a intensa luminosidade, passa a ter uma coloração avermelhada nos bordos. Predomina nos gradientes 2 e 4 .

Rhipsalis Gaertner, Nom. Cons. 


\section{Chave para Espécies}

1. Artículos cilíndricos

2. Artículos terminais delgados e com densa pilosidade

R. prismatica

2' Artículos terminais crassos e glabros ......... baccifera

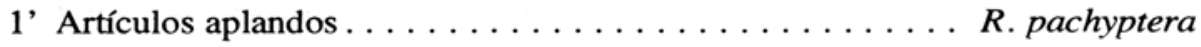

\section{Descrição das Espécies}

Rhipsalis prismatica (Lem.) Frost. et Ruempl. Handb. Cact. ed. 2: 884.1886; Schum. in Mart. Fl. Bras. 4(2): 299.1890, incertae sedis; Scheinvar, Cactáceas in Fl. Catar. 1:263. 1985.

Planta epífita muito ramificada, com aréolas distantes e com poucas cerdas. Flores rotáceas de mais ou menos $5 \mathrm{~mm}$ de comprimento e diâmetro na antese, esbranquiçadas. Fruto baga globosa, branco-rosado ou avermelhado, translúcido.

Nome vulgar: Comambaia (Sheinvar, 1985).

Material coletado: RFA no 22.089, C.M. Rizzini et al., 421. 9.V.1988, fl. e fr.; RFA no 22.090, C.M. Rizzini et al., 422. 9.V.1988, fl e fr.; RFA no 22.152, C.M. Rizzini et al., 432, 4.VII.1988, fr.; RFA no 18.540, P). Occhioni et al., 8307. 13.II.1982, fl.

Observações: Predomina no gradiente 2, onde se fixa abundantemente nos ramos das plantas. Ocorre também nos gradientes 4,5 e 6 , porém com menor freqüência. Em locais de vegetação fechada, onde a penetração de luz é menor, perde a coloração avermelhada e os ramos se tornam mais delgados.

Rhipsalis baccifera (Mill.) Stearn. in Adnot. Cact. Jour. 7:107. 1939; Scheinvar, Cactáceas in Fl. Catar. 1:239. 1985.

K. cassutha Gartner, Fruct. Sem. P1. 1:137. 1788.

Planta epífita, muito ramificada, inicialmente ereta, passando a pêndula; crassa e sublenhosa. Flores de 5-9 mm de comprimento, esbranquiçadas. Fruto baga subglobosa, violácea.

Nome vulgar: Erva-de-canário (Scheinvar, 1985).

Material coletado: RFA no 22.443, C.M. Rizzini et al., 452. 12.XII.1988, fr.; RFA no 22.537, C.M. Rizzini 445 et al., 25.X.1988, fl.; RFA no 22.153, C.M. 
Rizzini et al., 433. 4.VII.1988, fr.

Observações: Espécie só encontrada no gradiente 1, sobre árvores isoladas próximo de habitações.

Rhipsalis pachyptera Pfeiff. Enum. Diag. Cact.: 132. 1837; Schum., in Mart. Fl. Bras. 4(2): 292, T. 57.1890; Scheinvar, Cactáceas in Fl. Catar. 1:293. 1985.

Planta epífita com artículos grossos e aplanados, muito ramificada e com margens crenadas. Flores 1-3 em cada aréola, mais ou menos $13 \mathrm{~mm}$ de comprimento, esbranquiçadas. Frutos truncados no ápice, marrom-alaranjados.

Nome vulgar: Conanbaia (Correa, 1984), Comambaia (Scheinvar, 1985). Material coletado: RFA no 22.091, C.M. Rizzini et al., 423. 16.V.1988, fl.; RFA no 22.197, C.M. Rizzini et al., 439. 30.VIII.1988, fl.; RFA no 22.519, G. Azevedo 15A et al., 19.X.1988, fr; RFA no 22.535, C.M. Rizzini et al., 443. 25.X.1988, fr.

Observações: ocorre nos gradientes 4 e 5, em populações isoladas e esparsas.

A família Cactaceae está representada em Maricá por 11 espécies, distribuídas por 9 gêneros, sendo que o gênero Rhipsalis ocorre com 3 espécies e os demais com 1 espécie cada.

Os estudos realizados foram baseados em dados bibliográficos, coletas periódicas e levantamento nos principais herbários do Rio de Janeiro; mesmo assim, foi verificada a ocorrência de espécies que não haviam sido ainda indicadas para a região. Acredita-se que tal fato é devido à ocorrência rara de algumas destas espécies e pela resistência dos pesquisadores em coletá-las, fato comprovado pela ausência de coleções nos herbários consultados.

Foi verificado também que muitas das espécies conhecidas para a região são tratadas em vários trabalhos de levantamento de flora sob o epiteto específico incorreto e outras indicadas como ocorrendo lá, o que provavelmente trata-se de erros de identificação.

\section{Referências bibliográficas}

CORREA, M.P. 1984. Dicionário das plantas úteis do Brasil e das exóticas cultivadas. M. da Agricultura, Rio de Janeiro, vol. 2. 707 pp., vol. 3,646 pp.

RITTER, F. 1979. Kakteen in Suedamerika. Edição do autor, Spangenberg, Vol. 1.

RIZZINI, C.T. 1982. Melocactus no Brasil. Rio de Janeiro, IBDF. Jardim 
Botânico do Rio de Janeiro.

SHEINVAR, L. 1985. Cactáceas. Flora Ilustrada Catarinense.

SCHUMANN, K. 1890. Cactáceas. In: C.F.L. Martius. Mart. Fl. Bras. 4(2): 186-322. 